\title{
TRABALHO DOCENTE, GÊNERO E PODER EM DENÚNCIAS PÚBLICAS DA DÉCADA DE 1880
}

\author{
Clarice Nascimento de Melo \\ Universidade Federal do Pará (UFPA) \\ mnclarice@gmail.com
}

Karla Nazareth Corrêa de Almeida Universidade Federal do Pará (UFPA)

kalmeida@ufpa.br

\begin{abstract}
RESUMO
Este artigo procura capturar, nos debates que denunciam práticas supostamente irregulares de professores, as conexões da educação de mulheres com os referenciais de gênero produzidos na sociedade paraense em fins do século XIX. Tomam-se por objeto de estudo as contendas sobre o trabalho docente contidas em notas publicadas nos jornais de circulação local desse período. Com elas indicam-se falas que dimensionam o trabalho docente perpassadas por representações de gênero, na medida em que as práticas docentes denunciadas conformam tipos de comportamentos idealizados socialmente para a profissão de forma diferenciada para homens e mulheres.

Palavras-chave: Docência, gênero, poder. \section{COMPLAINTS OF THE DECADE 1880}

TEACHING WORK, GENDER AND POWER IN PUBLIC
\end{abstract}

\begin{abstract}
This article looks forward to capture, on the debates that detect supposedly irregular teaching practices, the connections of women's education and gender referential produced by the society from Pará at the end of the $19^{\text {th }}$ century. The objects of this study are the debating documents referring to the teaching work contained local circulation journals on that period. On these notes, quotes are indentified, quotes on teaching work that are pierced with genders representations, as these representations and the teaching practices are typical and idealized behavior for the teachers class, preconized for men and women classes.
\end{abstract} Key-words: Teaching, gender, power.

\section{Um Começo de Conversa}

O ingresso expressivo das mulheres paraenses no trabalho formal ocorreu no final da década de 70 do século XIX, em função do desenvolvimento econômico do estado fomentado pela produção da borracha. Esse movimento consolida a presença de mulheres na escola, seja como discente, seja como docente, o que repercute nos sinais deixados por elas, os quais se encontram nas fontes históricas, seja em relatórios de governo, seja nos jornais locais e até mesmo na legislação, aumentando a sua visibilidade, tornando possível a sua presença na educação ser objeto de estudo. Alguns trabalhos de pesquisadores que se 
debruçam sobre a história da educação paraense têm chamado a atenção para os modos dessa presença. Bezerra Neto trata o tema por meio das representações sobre as mulheres, destacando o exercício da dominação masculina no processo de construção da imagem feminina durante as últimas décadas do século XIX (BEZERRA NETO, 1995). Em outro trabalho, Bezerra Neto (1998) retoma o estudo da educação de mulheres, agora mais centrado no significado do Asylo Santo Antônio no contexto da educação iluminista. Já o trabalho investigativo de Cancela (2006) trata da escolarização feminina no Pará, nos anos de 1870 e 1880, para assessorar a análise sobre a distribuição de riquezas e as relações matrimoniais praticadas no estado. Rizzini (2004) remete-se à educação de mulheres de forma assessória, mediando um diálogo com seu objeto de estudo: a escolarização de meninos desvalidos. Sousa (2010) investe esforços na escrita da história da educação de meninas desvalidas no estudo que fez sobre instituições paraenses de atendimento a meninos e meninas desvalidas no final do século XIX e início do XX. A tônica de cada um desses estudos, além de focar as mudanças e as permanências da educação feminina na passagem do regime imperial para republicano, orienta-se na análise das práticas e das representações que envolvem o universo escolar feminino.

Com a intenção de ampliar esse universo de estudos sobre a educação de mulheres na sociedade imperial paraense, este texto procura capturar, nos debates que denunciam práticas supostamente irregulares de professores, as conexões do trabalho docente com os referenciais de gênero produzidos na sociedade paraense em fins do século XIX.

Tomam-se por objeto de estudo as contendas sobre práticas docentes contidas em notas publicadas nos jornais de circulação local desse período. Com elas indicam-se falas que dimensionam o a educação de mulheres perpassadas por significados sociais, não com o propósito de figurar uma veracidade nas denúncias, mas sim, interpretar no seu interior das práticas educativas moldadas por um contexto de cultura.

Essa opção é feita com base em alguns princípios que justificam a temática de estudo, a escolha das fontes, e principalmente, o modo de problematizá-las e analisá-las e sobre a qual me detenho por ora.

Este texto encontra-se na área da história da educação e se insere na dimensão da história social e no domínio "história das mulheres", conforme o quatro teórico proposto por Barros (2004). Filia-se à escrita da história cultural contemporânea, que localiza a história não em sujeitos individuais vinculados ao poder político, mas persegue as ações de pessoas comuns, com a preocupação de alcançar toda a atividade humana em sua construção social e cultural, focando o olhar não somente para as práticas políticoinstitucionais, mas principalmente para as práticas diárias. Isto é feito em busca, não de um desenvolvimento contínuo e linear dos acontecimentos, mas de uma história com mudanças e permanências, dando conta do que se convencionou chamar de história vista de baixo (BURKE: 1992).

E como afirma Fonseca:

A contribuição que a história cultural, como campo dotado de aportes teórico metodológicos, pode dar ao avanço da história da educação está no descortinamento de dimensões ainda pouco exploradas, fora da escola e da escolarização, bem como a imposição corajosa de novos olhares sobre essa que é uma dimensão já tradicional (FONSECA, Op.cit. p. 72).

A afiliação a este tipo de abordagem se justifica pelo fato de que a adoção dos objetos universais da historiografia clássica naturalizou uma história feita por homens ligados ao poder instituído e excluíram parte da história em que as mulheres vivenciaram experiências significativas. Trazer as falas sobre práticas docentes na perspectiva de gênero 
vai de encontro a essa abordagem, por colocar em destaque não só a vida de pessoas comuns que são denunciadas nos jornais, como também os valores sociais daquele tempo.

O trabalho pauta-se em uma história despreocupada com os grandes acontecimentos, que busca no passado os elementos para uma percepção da vida comum, rotineira, das pessoas em diferentes tempos e lugares. $\mathrm{O}$ olhar para o cotidiano é posto nos espaços de constantes disputas e conflitos, para situar ações singulares de mulheres no contexto da sociedade em que elas foram realizadas, bem como as falas que representam esse cotidiano. Esta abordagem privilegia os sistemas de valores e de normas relacionados à formação da sociedade paraense, bem como sua interferência no cotidiano, nas atitudes e modos de vida.

Com essa orientação, opta-se pela pesquisa documental como orientação metodológica do estudo, por se tratar de pesquisa histórica com utilização de fontes primárias documentais.

Os documentos são abordados conforme a conceituação de Le Goff (1992), como documento/monumento. A história tradicional rankeana, de cunho positivista, intenciona relatar apenas o que realmente aconteceu, dissociando o sujeito do objeto. Nesta perspectiva a história existe em si mesma, pois os documentos oficiais que garantiriam a verdade cientifica e objetiva. De modo inverso, as notícias de jornais encontradas nos arquivos foram lidas a partir de sua característica mais marcante: a de ser uma produção de homens e mulheres situados em locais de poder e que, portanto, sendo produto da sociedade que o fabricou e o conservou, traz consigo uma verdade parcial, situada na fala de quem o produziu e de quem o tornou um monumento, ou seja, de quem intencionalmente o marcou para constituir-se como uma marca da perpetuação de uma fala, de um sentido, de um poder.

$\mathrm{O}$ processo de análise documental foi tratado mediante a aproximação com o método indiciário, por onde as leituras documentais perseguem os nexos construídos entre o dito e o interdito nos documento, na procura de pistas e sinais imbricados nas linhas e sublinhas dos documentos, com a perspectiva de que a produção do conhecimento histórico é indireto e conjetural (GINZBURG: 1989); portanto, as conclusões apresentadas nos textos são postas como verdades provisórias, a partir da decifração dos vestígios encontrados no corpo documental e das interpretações das autoras. Procurou-se compreender a divulgação em jornais de denúncias sobre professores como um fenômeno peculiar desse tempo, buscando indícios para realizar inferências sobre os conceitos relativos à educação feminina que consideramos estar relacionados à questão de gênero.

Por sua vez, os jornais diários de circulação local foram lidos considerando sua capacidade de mostrar apenas parte da realidade educativa, bem como uma expressão das ações diárias dos sujeitos que produzem a educação, direta ou indiretamente. Com eles foi possível relacionar os projetos de sociedade com as realidades (NÓVOA: 1997).

$\mathrm{Na}$ medida em que as práticas docentes denunciadas conformam tipos de comportamento idealizado para a profissão, de forma diferenciada para homens e mulheres, destacam-se neste texto, por meio dessas notas, as diferenças de gênero que são postas nos interstícios da disputa política pelo poder local que configura um traço da sociedade imperial paraense, com base no conceito de gênero apresentado por Scott:

[...] o gênero é igualmente utilizado para designar as relações sociais entre os sexos. O seu uso rejeita explicitamente as explicações biológicas, como aquelas que encontram um denominador comum para várias formas de subordinação no fato de que as mulheres têm filhos e que os homens têm uma força muscular superior. O gênero se torna, aliás, uma maneira de indicar as "construções sociais": a criação inteiramente social das 
idéias sobre os papéis próprios aos homens e às mulheres. É uma maneira de se referir às origens exclusivamente sociais das identidades subjetivas dos homens e das mulheres. O gênero é, segundo essa definição, uma categoria social imposta sobre um corpo sexuado (SCOTT, 2012, p. 2).

Esse olhar expressa um traço compreendido no campo das subjetividades, na perspectiva que aponta Matos:

Os estudos sobre a subjetividade apresentam-se como uma nova fronteira para a historiografia [...] problematizam a noção de sujeito universal, unitário, isolável, emergindo a centralidade nos processos de diferenciação e nas possibilidades de construção singular da existência nas configurações assumidas pelas apreensões que os sujeitos fazem de si e do mundo (MATOS, 2001, p.47).

Move-se em torno das falas dos indivíduos que discorreram publicamente sobre comportamentos de seu tempo, localizando as versões que indicam visões de mundo que apontam conexões entre as práticas de docência feminina e as experiências sociais de seu tempo.

Como tema privilegiado neste texto, o trabalho docente nos faz pensar sobre aspectos relevantes do trabalho em sua relação com a sociedade, não mais focado no seu aspecto econômico, mas nos modos de viver o trabalho envolto a sinais da cultura que o sustenta (FONSECA, 2003).

Do mesmo modo, as práticas escolares são analisadas como lugar de sociabilidades, onde se atravessam as experiências de trabalho, nos permite compreender os consensos e as tensões construídas diariamente e formatam as experiências desse mundo do trabalho (FONSECA, Op.cit).

Portanto, pensar a educação com a fala dos supervisores que expressam em seus relatórios a visão de mundo dos que se responsabilizam pelo poder político central, ou refletir sobre educação por meio da fala dos legisladores é um dado importante, mas não é suficiente para mostrar as contradições e os embates da vida cotidiana. É também necessário buscar outras histórias que manifestam práticas educativas singulares que se mobilizam, às vezes num encontro, às vezes num desencontro com o que é instituído no universo das leis. A educação é praticada como um elemento de cultura. Os valores, as representações que cada sociedade constrói se imiscuem no cotidiano, conduzindo a forma com que a educação é configurada, tanto no universo da política, quanto no universo escolar.

Com esses nortes, segue o texto em três partes. A primeira trata do processo de inserção das mulheres no trabalho docente, destacando as representações que foram sendo construídas sobre elas. A segunda apresenta a fala institucional reguladora das práticas docentes, apontando os elementos que deveriam balizar o comportamento docente em acordo ao projeto social da escola. E, por fim, apresento os jogos de correção das práticas docentes empreendidos por populares e divulgados nos jornais, analisando as falas que indicam formas diferenciadas de tratar das práticas de educação de homens e mulheres, situadas por representações de gênero produzidas com as marcas da sociedade paraense do fim do século XIX. 


\section{Trabalho Docente, Mulher e Sociedade Imperial}

A permanência do tempo passado e do tempo presente pode ser percebida na sociedade imperial brasileira, seja do ponto de vista político, seja do ponto de vista social e cultural. De um lado, as marcas da sociedade colonial presente nas relações escravistas de produção, além da presença marcante da igreja sedimentando regras de comportamento. De outro lado, o processo de europeização baseado na ciência e nas "luzes" (PRIORE; VENÂNCIO, 2001); a campanha abolicionista, a campanha republicana e o movimento feminista dão a cara das rupturas que se avizinham no interior do projeto imperial brasileiro e paraense.

A década de 1880 se fez nesse cenário como um período de pulsantes debates nos campos político e educacional, que se configuram no interior das disputas em torno da manutenção do regime imperial ou da adoção do regime republicano. No campo educacional

A presença de professoras na escola paraense atravessa esse movimento nos oitocentos mediada pela paulatina saída paulatina dos religiosos da escola, ocorrida principalmente na capital. Por sua vez, a igreja permaneceu hegemônica no interior do Estado em virtude das dificuldades da contratação de pessoas para lecionar em escolas dos lugarejos e vilas distantes. Em 1850, por exemplo "das 42 cadeiras de instrução primária existentes no Pará, 11 eram regidas por padres, 27 por não religiosos e 4 por mulheres" (GONDRA; SCHUELER, 2008, p.160). Isto indica que as alianças feitas entre a igreja e a escola apontam para a sedimentação de uma moral religiosa, ao mesmo tempo em que os novos saberes científicos são introduzidos na escola.

Esse movimento foi se alterando ao longo da década de oitenta, em conformidade com o processo nacional de inserção das mulheres no mundo do trabalho docente, naquilo que se convencionou chamar de feminização do magistério.

O ofício docente, tradicionalmente exercido por homens, membros de ordens e corporações religiosas, militares e por intelectuais leigos, foi transformado com o ingresso das mulheres (GONDRA \& SCHUELER, op.cit, p.215).

Isso se explica, principalmente, pela ampliação da demanda feminina por educação e pelo princípio "moderno" da educação infantil que requeria a "professora-mãe" na sua dinamização. O movimento mais imediato, construído nacionalmente, ocorreu nas políticas de formação de professores, por onde se sedimentou o predomínio feminino nos cursos de magistério. O movimento de inserção de mulheres nos cursos de formação docente iniciado por volta de 1850 se consolidou no final do período imperial, quando o número de mulheres já era superior ao dos homens (VEIGA, 2007), permitindo a presença mais intensa das mulheres nas escolas.

Em um tempo em que a escola começou a ganhar sentido e importância social, as mulheres foram inseridas no mundo letrado e, para profissionalizá-las, na formação docente.

Nesse processo a sobrevivência, a permanência e a circulação de professoras na escola e na rua, ressignificou o olhar sobre a docência feminina, o que possibilitou a produção de novas representações de mulheres, de profissão docente e de escola (VIDAL; CARVALHO, 2001), naturalizando a relação entre o feminino e a docência, criando com isso a possibilidade maior das mulheres ocuparem o espaço urbano. Mas isto não se apresenta sem um sentido: a sociedade imperial agregou às mulheres no magistério, que 
tornou-se a profissão "natural" para o trabalho feminino, profissão compatível com o casamento e com a maternidade (MENDEZ, 2005).

A ampliação da presença das mulheres na escola deu visibilidade social a elas e as colocaram no jogo de poder instituído, o que as tornou, junto com os homens, alvos de juízos de valor, tanto do Estado, quanto da sociedade, que se manifestaram em acordo com as representações que se construíram sobre elas.

\section{As Balizas do Discurso Oficial}

Em um tempo de secularização e de estatização do ensino, o Estado brasileiro assumiu como responsabilidade a educação das crianças, o que lhe deu a incumbência de criar regulamentações do ensino, dos currículos e das práticas dos professores. Encontra-se no interior das regulamentações do ensino primário e secundário da época um corpo de prescrições que apontam os direitos e os deveres dos professores, que orientam as expectativas sociais.

Nota-se nas notícias de jornais que as denúncias encontradas formalizadas sobre as práticas de professores frequentemente baseiam-se no corpo legal para defini-las como incorretas. Isto porque o grupo de direitos e deveres atua sobre aspectos relativos ao comportamento moral e à atuação intelectual.

Por esta razão, coloca-se em destaque a Lei n. 1.030 de 7 de Maio de 1880, que reforma o ensino primário da província, que prescreve quais são os deveres dos professores:

Art. 26. Os professores públicos, além das obrigações declaradas n'esta lei, devem:

$1^{\circ}$ Manter nas escólas o silêncio, a exactidão e a regularidade necessária.

$2^{\circ}$ Apresentar-se ali decentemente vestidos e conservarem-se na aula até que todos os alumnos se tenham retirado[...] (PARÁ. Lei n. 1.030, de 7 de maio de 1880).

E em relação à docência particular:

[...] $\S 2^{\circ} \mathrm{O}$ director da instrucção publica na capital ou o delegado litterario no interior da província, poderá oppor-se á abertura da escola ou collegio no caso de falta de capacidade moral do professor ou por irregularidade de conducta ou por ter soffrido condemnação por crime infamante $[\ldots]$

[... $\S 4^{\circ}$ Se em qualquer collegio ou escola derem-se factos de immoralidade ou o director ou professor se tornar incompatível com o magistério, nos casos previstos no $\S 2^{\circ}$, poderá o director da instrucção publica ou o delegado litterario intimar que seja fechada a casa de educação, cabendo ainda d'esta decisão recurso para o presidente da província, como está prescrito no $\S$ antecedente.

(PARÁ. Lei n. 1.030, de 7 de maio de 1880).

Nas diretrizes legais, a decência aparece como um pressuposto básico do comportamento docente, isto por que: 


\begin{abstract}
O campo da instrução pública teve um papel destacado no processo de difusão da pedagogia da moralidade. A escola tinha e tem como objetivos formar e educar os indivíduos para ocupar seu lugar na sociedade: é, portanto, uma instituição fundamental no processo de produção/reprodução social. Inserida numa sociedade hierarquizada, restou a ela reproduzir no seu interior o conjunto dessas relações e, por extensão, devolver à mesma sociedade indivíduos que reproduziriam esses valores nas suas práticas quotidianas (CASTANHA, 2012, p.1).
\end{abstract}

A formação de uma sociedade letrada e moderna pressupunha a construção de uma nova mentalidade, que se caracteriza pelo que Elias (1994) chama de "processo civilizador", onde os bons costumes são a tônica do comportamento idealizado e a escola, na prática educativa dos professores, deveria consolidar.

$\mathrm{Na}$ mesma lei estão outras diretrizes que regulam as práticas dos professores, desta feita fundamentadas em proibições de caráter ético. Ainda aqui não estão mencionados os aspectos pedagógicos da prática docente. Como se vê no documento abaixo:
Art. 28. O professor publico não póde:
$1^{\circ}$ dar lição em sua casa ou em casas particulares aos alumnos de sua escola.
$2^{\circ}$ ter sua residência fora da cidade, villa ou povoação em que estiver a escola.
$3^{\circ}$ Occupar-se ou occupar os alumnos em misteres extranhos ao ensino, durante as horas das lições.
$4^{\circ}$ Ausentar-se nos dias lectivos para qualquer lugar distante, sem licença do delegado respectivo, o qual só a poderá conceder em caso urgente até 30 dias consecutivos.
$5^{\circ}$ Aceitar emprego ou cargo de nomeação provincial ou geral e municipal.
$6^{\circ}$ Exercer qualquer profissão commercial ou industrial [...](PARÁ. Lei n. 1.030 , de 7 de maio de 1880).

Percebe-se, ainda, que as parcas vantagens adquiridas pelos professores ao longo de seu exercício profissional, estão ancoradas no âmbito do Estado, além dos aspectos anteriormente indicados, em critérios de competência intelectual, conforme se vê no documento abaixo, o que expressa um movimento na valorização do saber docente que, se presume, estar associado à ampliação da formação docente, feminina e masculina, nos cursos normais.

Art. 29. O professor, que durante 5 anos de efetivo exercício tiver dado provas de capacidade intelectual e moral, mostrado dedicada vocação para o ensino, sem nunca ter incorrido nas censuras de seus superiores, terá o provimento vitalício, depois de ouvido o conselho diretor.

Art.30. Aos professores elementares, que tiverem 8 anos de bons serviços, com as condições exigidas no art. antecedente, poderá concedida a vitaliciedade na cadeira, ouvido o conselho diretor (PARÁ. Lei n. 1.030, de 7 de maio de 1880). 
Nesses elementos destacados percebe-se, também que há regulamentação sobre o modo de exercer a profissão docente, que vai do controle sobre a ação pedagógica, que diz respeito a sua freqüência na escola e não ministrar aulas particulares a seus alunos, até ao controle do comportamento moral, como em relação à vestimenta adequada, a prática de atos considerados de imoralidade e, mesmo, à sua conduta social.

Em síntese, as imagens do professor do final do século XIX passaram a ser associadas ao discurso científico e a boa qualidade moral, com conhecimento pedagógico e disponibilidade de tempo exclusivo para o magistério (DURÃES, 2011, p.471).

Como se notará em seguida são esses os nortes que mediam as preocupações dos denunciantes que, revelando em algumas vezes um caráter político em suas falas, e procurando mostrar as falhas da direção do ensino por meio das práticas apontadas como contrárias ao que diz a lei, indicam modos diferenciados de representar a docência masculina e a feminina.

\section{Jogos de Correção}

A ampliação das regulamentações da instrução pública no final do século XIX é visível no corpo documental, o que indica a razão de terem sido elas palco de discussões em torno da eficácia do Estado em relação à qualificação da "instrução pública".

Em torno dela apontam as disputas políticas impressas nos jornais locais que se configuram, em primeira mão, como institucionais, mas que revelam, em uma leitura mais atenta, as disputas de poder locais que se espraiam para além do político e alcançam vida da escola, mesclada na vida de professores e professoras. O debate entre os conservadores e os republicanos é exposto publicamente nos jornais de circulação local de diversas formas, ora colocando em cheque as diretrizes da educação pautadas nas legislações, ora apontando falha na organização do ensino, ora colocando em discussão as práticas educativas escolares. Esse debate político abarca o cotidiano das escolas e da sociedade, na medida em que as falas que apontam as críticas à educação alcançam as raias dos partidos políticos, como se vê na fala que critica o professor nominando-o de "cabide do partido conservador da localidade" (O LIBERAL DO PARÁ, Belém, 16 nov. 1887, p.2).

A grande maioria de denunciados nos jornais são professores, o que não se explica pelo número de escolas masculina e feminina no estado, pois em 1883 o número de escolas femininas já era superior às masculinas, pois das 27 escolas públicas existentes, 11 eram do sexo masculino, com matrícula de 819 alunos, e 16 eram do sexo feminino, com 1.320 alunas matriculadas (O LIBERAL DO PARÁ. Belém, 25 mar. 1882). A educação feminina está em expansão tanto na esfera pública quanto na privada. Pela característica das falas, presume-se o que o que possa explicar este fato seja a relação mais direta que os professores possuem em relação ao poder político, o que os torna mais suscetíveis de crítica.

As relações de poder que se apresentam no embate e na disputa diária, nas relações cotidianas entre os sujeitos que configuram modos de resistência e contestação (LOURO, 1991). As falas dos sujeitos divulgadas nos jornais locais aparecem muito mais nas suas potencialidades cotidianas, mas se revelam como ações mobilizadas constantemente pelas esferas político-institucionais.

As notícias dos jornais, em diversas vezes, querem mostrar que as leis que orientam ações docentes são constantemente transgredidas e que o Estado não cumpre sua função regulatória. Nas denúncias que vêm de vários locais, principalmente do interior do estado, os reclamantes rechaçam práticas docentes que consideram inadequadas à instrução 
pública; reclamam da existência de professores e professoras analfabetos/as, de saídas da escola fora de hora e do dia correto, de troca de município à revelia da lei e das exigências da sociedade, entre outras.

Tomam-se como exemplo, alguns casos que dão pistas sobre os modos que os poderes locais, na fala dos jornais, divulgam idéias sobre práticas de educação, por onde se afirma que estão envoltas por representações de gênero.

Na Freguesia de São Sebastião da Boa Vista, no artigo assinado por "um pai de família", o professor Bellarmino Malheiros de Mello é acusado de desviar-se do regulamento vigente no exercício do magistério. Acusado de faltar aulas, é considerado:

[...] homem de maus costumes, sem educação, nem qualidade que o [?] a tomar direção de casa, educação de meninos que hoje recebem a instrução para logo mais dar a seus descendentes; a escola entregue a este malvado, não freqüenta as horas que preceitua o art. 29 do regulamento de 13 de janeiro de 1874, as mais das vezes o tal substituto não comparece a escola, e como não acontecer assim, pois se ele é empregado da coletoria geral da extinta câmara municipal [...] (A CONSTITUIÇÃO, Belém, 7 fev. 1875, p.2).

A crítica posta em relação aos maus costumes e a sua pretensa deseducação revela uma demanda social pautada no valor civilizatório da sociedade que se queria moderna, e na qual a escola deveria se pautar. Um professor com essas características não pode "tomar a direção de casa, educação de meninos", pois esses meninos, segundo o autor, devem estar em uma escola que divulgue os bons costumes não só para essa geração, como para as outras subsequentes. Essa deveria ser a tarefa da escola no fim do império e essa é a tarefa dos sujeitos que dela devem participar. Do professor é solicitado que cumpra, com o seu comportamento, o seu papel na construção da escola moderna. A denúncia traduz o ideário civilizador desse tempo propagandeado por "grupos sociais que idealizavam a educação e a religião como estratégias na relação de poder, para estabelecer um comportamento social individual e coletivamente aceitável" (OLIVEIRA, 2009, p.2). Essa tarefa é traduzida na figura masculina. $\mathrm{O}$ professor, educador de meninos deveria consolidar para as gerações seguintes, as experiências de uma sociedade moderna. Ainda mais, a sua falha está associada à maldade, considerada culturalmente própria do masculino, em oposição à bondade, culturalmente própria do feminino

De forma diferente, o mesmo pai de família reclama da professora normalista Adélia do Carmo Tavares que "também deixou de dar escola no dia 16; visto que seu marido é o chefe dos homens do vintém e foi quem presidiu a palhaçada desse dia" (A CONSTITUIÇÃO, Belém, 7 fev. 1875, p.2), referindo-se à cerimônia de juramento que prestaram os novos alferes do batalhão 21 que, de acordo com o denunciante, era chefiado pelo marido da professora.

Note-se que, tendo a professora o diploma de normalista e, portanto formalmente apta para conduzir sua escola, a crítica feita ao seu comportamento não está associada aos seus modos individuais ou mesmo à sua forma de praticar à sua maneira de ser e agir pedagogicamente. A crítica que destaca a sua ausência na escola não é associada à negligência pessoal, mas sim à sua condição de esposa de alguém ligado ao poder local. A professora, neste caso, é subsumida à sua condição de esposa e, portanto, sem autonomia.

De outra notícia vem a denúncia de que na localidade, Igarapé Janahú-assú, em Mojú, a escola do lugar não possui funcionamento regular em virtude, entre outros, "porque o professor está ordinário em férias e passeiando" e que de Igarapé Jary, em Capim, o professor do ensino elementar, Joaquim de Oliveira, retirou-se para a capital do 
estado, presumivelmente, sem licença oficial (A CONSTITUIÇÃO, Belém, 17 mar. 1881, p.1).

Em outra nota vem a notícia de que na escola primária do sexo masculino de $\mathrm{S}$. Domingos da Boa Vista, "o professor, conquanto não seja da laia dos prediletos do Sr. B. de Marajó, tem a mais completa negação para o magistério, pelo que pudesse dizer que é professor somente para receber o seu ordenado. A escola está de contínuo abandonada, entregue aos meninos" (A CONSTITUIÇÃO, Belém, 17 mar. 1881, p.1).

Em ambas as notícias o que se percebe são denúncias que, subliminarmente, as práticas dos docentes estão relacionadas ao descontrole do Estado em relação ao funcionamento das escolas. Sabe-se que o controle é um princípio da escola moderna, amplamente divulgado na legislação.

De modo diferente, as práticas de mulheres aparecem relacionadas ao seu próprio comportamento e às suas características pessoais. Isto é perceptível na nota reclamante da escola do sexo feminino de Gurupá. Segundo um denunciante, a escola possui uma "professora respeitável, mas falta-lhe absolutamente habilitação para o magistério, o que bem conhecem os pais de família, e por isso deixam de mandar suas filhas a escola" (A CONSTITUIÇÃO, Belém, 27 jul. 1881, p.1). A crítica feita professora pretende ressaltar sua desqualificação profissional, mas ressalta que preenche o requisito moral. A diminuta participação das meninas na escola é relacionada à má formação da professora, pois, segundo o autor da denúncia os pais "deixam de mandar suas filhas a escola" por saberem da falta de "habilitação para o magistério", mas reafirma-se, a característica considerada indispensável às mulheres, o comportamento respeitável, é uma qualidade ressaltada. Isto pode ser percebido na tendência do final do século XIX de conceber a mulher como um ser desprovido de capacidade intelectual (ALVES, 2011, p.2).

De outro modo, lê-se no jornal duas notícias que indicam problemas na escola em virtude da idade das professoras.

Diz a primeira nota que as professoras substitutas da escola do sexo feminino de Vigia são jovens que se confundem com as alunas, "sendo mesmo provável que brinquem com elas" (O LIBERAL DO PARÁ, Belém, 4 out. 1885, p.2).

Nessa mesma direção, destaca-se a reclamação do pretenso escândalo que ocorreu na escola do sexo feminino de Abaeté, por ser a professora nomeada, ser analfabeta e uma criança. E ainda, “consta que n'esta escola, o que as meninas sabem de cor e salteado é as martinhadas de Bocage". Note-se que a referida professora é, ainda segundo o denunciante, esposa do "cabide do partido conservador da localidade" (O LIBERAL DO PARÁ, Belém, 16 nov. 1887, p.2). Logo, nesse caso, a sua permanência na escola está associada á sua condição de esposa e sua ligação ao poder local.

Nessas falas percebe-se que a juventude é associada à fragilidade, característica frequentemente associada à figura feminina e que, por isso, a professora não possui autoridade sobre as alunas. Também reitera a sua incapacidade intelectual, pois, segundo o denunciante, não privilegia o ensino dos conteúdos de ensino às meninas, e sim "as martinhadas de Bocage".

Nesse caso duas características consideradas próprias ao feminino desqualificam a prática educativa das professoras: a sua condição maternal (pois são consideradas crianças e, portanto, não são mães) e a sua capacidade intelectual. No final do século XIX as professoras deveriam possuir, ao mesmo tempo, condição maternal e conhecimento profissional do método (DURÃES, Op. Cit).

Esta preocupação não aparece nas denúncias de infração masculina. Os professores pecam, na fala dos denunciantes, por serem homens "de maus costumes, sem educação", portanto não possuem as características associadas a valores indispensáveis na 
sociedade paraense em busca da modernidade. Nas denúncias de professores não foi encontrada nas falas nota relativa a questões relacionadas à questões de moralidade.

Outra diferença diz respeito à relação feita entre às práticas docentes não aceitáveis ao poder político. Os professores são associados diretamente ao poder, pertencendo ou não ao grupo político instituído; as professoras, por sua vez, são relacionadas a ele por meio de seus cônjuges.

Professoras respeitáveis são as mulheres adultas, mães e esposas. As jovens não expressam a imagem ideal de professora do século XIX.

As falas apresentadas nos jornais, como se destacou, dialogam com os papéis idealizados para homens e mulheres construídas socialmente; as práticas de educação se originam e dialogam com esses referenciais.

\section{Considerações Finais}

Ao longo do artigo as práticas de professores e professoras vieram à tona por meio do que foi dito sobre elas nos jornais locais. Chama a atenção o volume e a freqüência de reclamações apresentadas por pessoas de diversas localidades do Estado, sobre a educação, principalmente a pública. E chama também a atenção que dentre as reclamações apareçam aquelas pautadas na figura dos professores e que são aparentes as formas de reclamar de professor e de professora. Para problematizar esta questão, elas são inseridas processo de inserção das mulheres no trabalho docente e das representações que foram sendo construídas sobre elas no tempo em que se construíram.

Recorre-se à fala institucional da lei que procura regulamentar as práticas docentes, apontando os elementos que norteadores do comportamento docente, situando-as em acordo ao projeto social da escola.

Por fim, são trazidas as falas que indicam as formas diferenciadas de tratar as práticas de educação de homens e mulheres, situadas por representações de gênero produzidas com as marcas da sociedade do século XIX.

Com esse percurso, percebe-se que as transgressões apresentadas publicamente desvendam, subliminarmente, as formas de resistências, de não submissão ao poder instituído. Ao mesmo tempo nota-se que os dissensos expressos nas práticas e nas falas dos jornais estão permeados dos sentidos que possuem socialmente as práticas docentes no interior de uma sociedade em alteração que se quer moderna. Revelam mais ainda, não apenas a pouca fortaleza e a fragilidade das leis e das normas de cultura, mas indicam lugares de experiências contraditórias que desafiam o poder, ao mesmo tempo em que criam outros círculos e lógicas de poder, situadas nas práticas cotidianas.

Voltar o olhar para a vida do trabalho nos faz pensar sobre aspectos relevantes do trabalho docente em sua relação com a sociedade, e neste caso específico, que ele espelha as diferenças de gênero e diferentes modos de pensar e produzir gêneros. As idéias mobilizadas nas denúncias sobre as práticas docentes consideradas incorretas estão de acordo com o lugar que os professores e as professoras ocupam na sociedade e das imagens que são construídas sobre eles/as na sociedade paraense no século XIX.

\section{Referências}

A CONSTITUIÇÃO. S. Sebastião da Bôa Vista. 20 de fevereiro de 1880. Belém, 27 de fevereiro de 1880, n. 30.

A CONSTITUIÇÃO. Instrucção pública (1). Belém, 17 de março de 1881. 
A CONSTITUIÇÃO. Instrucção pública (2). Belém, 17 de março de 1881.

A CONSTITUIÇÃO. Instrucção pública. Belém, 27 de julho de 1881.

ALVES, Maria Angélica. A educação feminina no Brasil entre os séculos XIX e XX: imagens da mulher intelectual. p.1-10. Disponível em: http://www.sbhe.org.br/novo/congressos/cbhe2/pdfs/Tema5/0540.pdf Aceso em dezembro de 2011.

BARROS, José D'Assunção. O campo da história: especialidades e abordagens. Petrópolis-RJ: Vozes, 2004.

BEZERRA NETO, José Maia. O asylo lindo e protetor: práticas e representações sociais sobre a educação feminina - Belém (1870/1888). In: ÁLVARES, Maria Luzia Miranda (Org.). A mulher existe? Belém: GEPEM/GOELDI, 1995. p.3-25.

. As luzes da instrução: o asylo de Santo Antônio em Belém do Pará (1870/1912). In: ACEVEDO MARIN, Rosa Elizabeth (Org.). A escrita da história paraense. Belém: NAEA/UFPA, 1998. p.185-205.BURKE, Peter, (Org.). A escrita da história: novas perspectivas. São Paulo: UNESP, 1992.

BURKE, Peter, (Org.). A escrita da história: novas perspectivas. São Paulo: UNESP, 1992.

CANCELA, Cristina Donza. Casamento e relações familiares na economia da borracha (Belém, 1870-1920). São Paulo-SP. 2006. Tese (Doutorado em História Econômica) Universidade de São Paulo, São Paulo, 2006.

CASTANHA, André Paulo. Moralidade pública e educação no século XIX. In: Anais do VI Congresso Brasileiro de História da Educação, 2011. Disponível no site: www.sbhe.org.br/.../Andre\%20Paulo\%20Castanha\%20-\%20Texto.pdf. Acesso em dezembro de 2011.

DURÃES, Sarah Jane Alves. Aprendendo a ser professor(a) no século XIX: algumas influências de Pestalozzi, Froebel e Herbart. In: Educação e Pesquisa. São Paulo, v.37, n.3, p. 465 - 480, set./dez. 2011.

ELIAS, Norbert. O processo civilizador. vol 1. Uma história dos costumes. Tradução de Ruy Jungmann. Rio de Janeiro: Jorge Zahar Ed., 1994. 2v.

FERREIRA, Ana Luiza de Oliveira Duarte. Ser Stella: um estudo sobre o papel da mulher e da educação feminina na Juiz de Fora do início do XX. In: Revista Brasileira de História da Educação. Campinas, $1^{\circ}$ número, Autores Associados, 2001.

FONSECA, Thais Nivia de Lima e. História da Educação e História Cultural. In: VEIGA, Cynthia Greive; FONSECA, Thais Nivia de Lima e. (Orgs.). História e Historiografia da Educação no Brasil. Belo Horizonte: Autêntica, 2003.

GINZBURG, Carlo. Mitos, emblemas e sinais. São Paulo: Companhia das Letras, 1989.

GONDRA, José Gonçalves \& SCHUELER, Alessandra. Educação, poder e sociedade no império brasileiro. São Paulo: Cortez, 2008.

LE GOFF, Jacques. História e memória. Campinas: Editora da UNICAMP, 1992.

LOURO, Guacira Lopes. Nas redes do conceito de gênero 1991. In: Lopes, M. J., Meyer, D.E. e Waldow, V.R. Gênero e Saúde. Porto Alegre, Artes Médicas, 1996 
MATOS, Maria Izilda Santos de. Por uma história das sensibilidades: em foco a masculinidade. In: História: questões \& debates, n. 34. Curitiba: Editora da UFPR, 2001. p.45-63.

MENDEZ, Natalia Pietra. Do lar para as ruas: capitalismo, trabalho e feminismo. Disponível em: http://www.fee.rs.gov.br/sitefee/download/mulher/2005/artigo3.pdf. Acesso em: outubro/2007.

NÓVOA, António. A imprensa de educação e ensino. In: CATANI, Denice Bárbara; BASTOS, Maria Helena Câmara (org.). Educação em revista - A imprensa periódica e a educação. São Paulo: Escrituras, 1997. p.11-32.

O LIBERAL DO PARÁ. Belém, 25 de março de 1883.

O LIBERAL DO PARÁ. Vigia, 27 de setembro. Belém, 4 de outubro de 1885.

O LIBERAL DO PARÁ. A instrucção pública é um myto, Belém, 16 de novembro de 1887.

OLIVEIRA, Lilian Sarat de. Educadoras e religiosas no Brasil do século XIX nos caminhos da civilização. XII Simpósio Internacional Processo Civilizador, 2009. Disponível em http://www.uel.br/grupoestudo/processoscivilizadores/portugues/sitesanais/anais12/artigos/pdfs/comunicacoes/C_ Oliveira3.pdf . Acesso em março de 2012.

PARÁ. Lei n. 1.030, de 7 de maio de 1880.

PRIORE, Mary Del \& VENÂNCIO, Renato Pinto. O livro de ouro da história do Brasil: do descobrimento à globalização. Rio de Janeiro: Ediouro, 2001.

SCOTT, Joan. Gênero: uma categoria útil para a análise histórica. Tradução de Christine Rufino Dabat e Maria Betânia Ávila. Disponível no sítio http://disciplinas.stoa.usp.br/pluginfile.php/6393/mod_resource/content/1/G\%C3\%AAnero -Joan\%20Scott.pdf. Acesso em: março de 2012.

SOUSA, Celita Maria Paes de. Traços de compaixão e misericordia na história do Pará: instituições para meninos e meninas desvalidas no século XIX até início do século XX. 2010. Tese. (Doutorado em Educação: Currículo) - Pontifícia Universidade Católica (PUC-SP), São Paulo, 2010.

VEIGA, Cynthia Greive. História da educação. São Paulo: Ática, 2007.

VIDAL, Diana Gonçalves; CARVALHO, Marília Pinto. Mulheres e magistério primário: ambigüidades e deslocamentos. In: VIDAL, Diana Gonçalves; HILSDORF, Maria Lúcia Spedo (org.). Brasil 500 anos: tópicas em história da educação. São Paulo: Editora da Universidade de São Paulo, 2001.

Recebido em novembro/2012

Aprovado em dezembro/2012 